\title{
Cinética de secagem de folhas de erva baleeira (Cordia verbenacea DC.)
}

GONELI, A.L.D. ${ }^{* ;}$ NASU, A.K.'; GANCEDO, R.1; ARAÚJO, W.D.'; SARATH, K.L.L.1

${ }^{1}$ Faculdade de Ciências Agrárias, Universidade Federal da Grande Dourados, Rodovia Dourados-Itahum, km 12, Campus Universitário, Caixa-Postal 533, CEP: 79.804-970, Dourados, MS - Brasil *andregoneli@ufgd.edu.br

\begin{abstract}
RESUMO: O objetivo do presente trabalho foi avaliar a cinética de secagem das folhas de erva baleeira (Cordia verbenacea DC.) bem como ajustar diferentes modelos matemáticos aos valores experimentais de razão de umidade. As folhas de erva baleeira foram colhidas com teor de água inicial de $75 \%$ b.u., sendo submetidas à secagem sob condições controladas de temperatura $\left(40,50,60\right.$ e $\left.70^{\circ} \mathrm{C}\right)$, até o teor de água aproximado de $10 \%$ b.u.. Aos dados experimentais foram ajustados oito modelos matemáticos citados na literatura específica e utilizados para a representação do processo de secagem de produtos agrícolas. Com base nos resultados obtidos pôde-se concluir que o modelo de Midilli é o que melhor representa a cinética de secagem das folhas de erva baleeira. O aumento da temperatura do ar de secagem promoveu maior taxa de remoção de água do produto. O coeficiente de difusão efetivo aumenta com a elevação da temperatura, sendo que sua relação com a temperatura de secagem pode ser descrita pela equação de Arrhenius. A energia de ativação para a difusão líquida durante a secagem das folhas de erva baleeira foi de $62,89 \mathrm{~kJ} \mathrm{~mol}^{-1}$.
\end{abstract}

Palavras-chave:Modelo de Midilli, Modelagem matemática, Razão de umidade, energia de ativação

ABSTRACT: Drying kinetics of Cordia verbenacea DC. leaves - The objective of the present work was to evaluate the drying kinetics of Cordia verbanacea DC. leaves, as well to fit different mathematical models to the experimental data of the moisture ratio. The Cordia verbanacea Dc. leaves wers harvested with initial moisture content of approximately $75 \%$ w.b. and submitted to the drying process under controlled conditions of temperature $\left(40,5060\right.$ and $\left.70^{\circ} \mathrm{C}\right)$, until the approximate moisture content of $10 \%$ w.b. Eight mathematical models mentioned or the specific literature were fitted to the experimental data and used to predict the drying process of the agricultural products. Based on the results obtained,swe have concluded that the Midilli model was the one that best represents the drying kinetics of Cordia verbanacea leaves. The temperature increase of the drying air promotes higher removal rate of water from the product. The effective diffusion coefficient increases with temperature elevation,tand its relationship with the drying temperature can be described through the Arrhenius equation, which presents activation energy of $62.89 \mathrm{~kJ} \mathrm{~mol}^{-1}$ for the liquid diffusion during the drying of the Cordia verbanacea DC. leaves.

Keywords: Midilli model, mathematical modeling, moisture ratio, activation energy.

\section{INTRODUÇÃO}

As plantas medicinais e aromáticas são matéria prima principal de grande quantidade de indústrias de alimentos, cosmética e farmacêutica. Seu uso é bastante disseminado entre a população brasileira, sendo vários os fatores que colaboram no desenvolvimento de práticas de saúde que incluam plantas medicinais, dentre elas o baixo custo da utilização da medicina caseira e as propriedades terapêuticas provenientes dos princípios ativos.
A utilização de plantas com fins medicinais, para tratamento, cura e prevenção de doenças, é uma das mais antigas formas de prática medicinal da humanidade. No início da década de 90 , segundo a Organização Mundial de Saúde (OMS), 65-80\% da população dos países em desenvolvimento dependiam das plantas medicinais como única forma de acesso aos cuidados básicos de saúde (Veiga Junior et al., 2005). 
A produção de fitoterápicos a partir de plantas medicinais e aromáticas requer, necessariamente, estudos prévios relativos a aspectos botânicos, agronômicos, fitoquímicos, farmacológicos, toxicológicos, de desenvolvimento de metodologias analíticas e tecnológicas (Miguel \& Miguel, 2004).

Dentre as várias espécies de plantas medicinais conhecidas no Brasil, a erva baleeira (Cordia verbenacea DC.) é uma planta medicinal nativa do Brasil, amplamente encontrada ao longo da costa sudeste do país. A parte aérea da planta é utilizada na medicina popular devido as suas propriedades antiinflamatórias e cicatrizantes, bem como no tratamento de artrite, reumatismo, tendinite, dores musculares e contusões.

A espécie Cordia verbenacea DC. possui folhas aromáticas, que são utilizadas na medicina popular como anti-infamatório, analgésico e antiulcerogênico, sob a forma de chás ou infusões para uso interno ou tópico (Lorenzi \& Matos, 2008). Ensaios farmacológicos dos extratos confirmaram suas propriedades medicinais como as ações anti-úlcera, antiinflamatória e cicatrizante (Sertié et al., 1988; Sertié et al., 2005; Ticli et al., 2005; Passos et al., 2007). Além disso, estudos também comprovaram que o óleo essencial obtido a partir da erva baleeira possuem ação antimicrobiana (Carvalho Júnior et al., 2004).

Estudos indicam que esta planta contém substâncias antiinflamatórias cuja efetividade e reduzidos efeitos colaterais a colocam como uma alternativa segura e eficaz no tratamento tópico de inflamações. Em 2005, o Laboratório Aché lançou o primeiro antiinflamatório fitoterápico, desenvolvido inteiramente no Brasil, obtido a partir do óleo essencial da planta Cordia verbenacea através da extração por arraste de vapor. O produto se apresenta na forma de creme com o nome comercial de Acheflan $®$.

Normalmente, a principal matéria prima para a obtenção de produtos fitoterápicos é a parte aérea das plantas medicinais e aromáticas. Independente da parte da planta que for ser colhida, estas normalmente são colhidas com elevado teor de água, sendo este o principal responsável pela má conservação pós-colheita do produto, uma vez que a água é o mais importante agente no aumento de atividades metabólicas e mudanças químicas e físicas que ocorrem no produto durante o armazenamento. Assim, objetivando a manutenção de sua qualidade pós-colheita, bem como a manutenção de seus compostos que irão ser utilizados na produção de fitoterápicos, é fundamental que as plantas medicinais tenham imediatamente seu teor de água reduzido após a colheita. Nesse contexto, a secagem é o processo mais utilizado para assegurar a qualidade e estabilidade após a colheita.

A secagem consiste em um complexo processo que envolve a transferência de calor e massa entre o ar de secagem e o produto a ser seco, onde o aumento da temperatura provoca o aumento da pressão parcial de vapor no produto, provocando a redução do teor de água. $O$ processo de secagem nas espécies medicinais é uma operação de fundamental importância para o armazenamento e conservação das plantas medicinais e aromáticas a serem utilizadas pela indústria farmacêutica de fitoterápicos (Lorenzi \& Matos, 2008). As condições de secagem e armazenamento são muito importantes para manter a qualidade destes produtos, sendo que as plantas medicinais e aromáticas devem ser submetidas imediatamente a secagem após a colheita (Soysal \& Öztekin, 1999).

Apesar de tradicionalmente realizada à sombra ou em secadores artesanais, a secagem de plantas medicinais utilizando secadores de maior eficiência pode ser considerada com uma das principais alternativas pensando-se em produções de extratos fitoterápicos em escala comercial, considerando o volume de produção necessário e o controle das variáveis do processo que interfiram na qualidade final do produto e ou subproduto.

A maioria dos estudos relacionados à secagem de produtos agrícolas se refere ao efeito de diversas variáveis externas como a temperatura do ar, umidade relativa, velocidade do ar dentre outras sobre o produto durante sua perda de água. Para tanto, modelos matemáticos são utilizados para representar a cinética de secagem frente a estas condições, sendo estes fundamentais para simulações matemáticas de camadas espessas de produto, que irão auxiliar no projeto de novos secadores ou no aperfeiçoamento de secadores já em operação (Berbert et al., 1995).

Existem três tipos de modelos de secagem usados para descrever a cinética de secagem de produtos agrícolas. O modelo teórico, que considera apenas a resistência interna a transferência de calor e água entre o produto e o ar quente, os modelos semi-teóricos e os empíricos, que consideraram somente a resistência externa a temperatura e umidade relativa do ar de secagem (Midilli et al., 2002; Panchariya et al., 2002).

Os modelos semi-teóricos são geralmente derivados da simplificação da segunda lei de Fick, oferecendo facilidade de uso, mas sendo válidos somente para as faixas de temperatura, umidade relativa, velocidade do ar e teor de água em que eles foram obtidos (Panchariya et al., 2002; Ozdemir \& Devres, 1999). Os modelos empíricos de secagem apresentam uma relação direta entre o teor de água do produto e o tempo de secagem. Eles negligenciam

Rev. Bras. PI. Med., Campinas, v.16, n.2, supl. I, p.434-443, 2014. 
os fundamentos do processo de secagem e seus parâmetros não têm qualquer significado físico. Dessa forma, os modelos empíricos não fornecem uma perspectiva dos importantes processos que ocorrem durante a secagem, embora em alguns casos possam descrever as curvas de secagem para determinadas condições experimentais (Keey, 1972).

Dentre os modelos teóricos aplicados ao processo de secagem, o modelo da difusão é o mais intensamente investigado. Este modelo considera como mecanismo principal a difusão baseada na segunda Lei de Fick, o qual descreve que o fluxo de massa por unidade de área é proporcional ao gradiente de concentração de água (Park et al., 2002). A difusão em produtos agrícolas durante a secagem é um complexo processo que pode envolver diferentes mecanismos, como a difusão molecular, difusão capilar, difusão na superfície, fluxo hidrodinâmico, difusão de vapor e difusão térmica. Uma vez que os modelos baseados na segunda Lei de Fick não são rigorosamente representativos dos diversos mecanismos que prevalecem no transporte de água em produtos agrícolas, o coeficiente de difusão determinado é considerado aparente ou efetivo (Roca et al., 2008). Outro fator que contribui para a complexidade do mecanismo de difusão é a diversidade da composição química e a estrutura física dos produtos. Dessa forma, os dados disponíveis na literatura apresentam elevada variação nos seus valores, não só devido à complexidade dos produtos, como também em função dos diferentes métodos de estimação, tipo de material, teor de água, processo de secagem e metodologia utilizada para sua obtenção (Zogzas et al., 1996).

Dessa forma, o presente trabalho foi desenvolvido com o objetivo de, ajustar e modelar, estatisticamente os modelos matemáticos e suas características termodinâmicas durante a cinética de secagem de folhas da erva baleeira.

\section{MATERIAL E MÉTODO}

O presente trabalho foi realizado no Laboratório de Propriedades Físicas de Produtos Agrícolas da Universidade Federal da Grande Dourados, no município de Dourados, MS. Foram utilizadas folhas da parte aérea de erva baleeira, colhidas no Horto de Plantas Medicinais - HPM da Faculdade de Ciências Agrárias da Universidade Federal da Grande Dourados - UFGD. A exsicata está depositada no Herbário DDMS da UFGD sob registro 4884.

As folhas da parte aérea de erva baleeira foram colhidas sempre nas primeiras horas da manhã e nunca após alguma precipitação pluviométrica ou irrigação, com a finalidade de evitar variação no teor de água inicial das mesmas. Após serem aleatoriamente colhidas, as folhas eram homogeneizadas para se evitar qualquer tipo de interferência nos resultados, bem como eliminadas aquelas que apresentaram algum tipo de dano físico ou sintoma de doença aparente. Para cada uma das temperaturas de secagem utilizadas neste trabalho foi realizada uma coleta, sendo colhidas, aproximadamente, $300 \mathrm{~g}$ de folhas em diferentes locais e plantas no Horto. Depois de feita a seleção e homogeneização, parte do material colhido era destinado à determinação do teor de água e outra parte de, aproximadamente, $25 \mathrm{~g}$ por repetição, era colocada para ser seca. O teor de água das amostras foi determinado pelo método gravimétrico recomendado pela Asabe (2010), para forrageiras e plantas similares, em estufa com circulação forçada de ar a $103 \pm 1{ }^{\circ} \mathrm{C}$, durante $24 \mathrm{~h}$.

A secagem do produto foi realizada para diferentes condições controladas de temperatura $\left(40,50,60,70^{\circ} \mathrm{C}\right)$, onde foram atingidas, em média, as seguintes umidades relativas do ar de secagem: $20,12,7$ e $3 \%$, respectivamente. Para a secagem da parte aérea das folhas de erva baleeira, utilizou-se uma estufa de esterilização e secagem da marca Nova Ética, modelo 400/5ND, com ventilação forçada e capacidade de 150 litros. No interior da estufa, a parte aérea de erva baleeira era acondicionada dentro de saquinhos quadrados de $15 \times 15 \mathrm{~cm}$ de tecido do tipo organza, impermeável à água, confeccionados especificamente para este fim. Os saquinhos contendo o produto eram dispostos em bandejas metálicas removíveis com fundo telado para permitir a passagem do ar através da camada de produto, sendo utilizadas duas bandejas com dois saquinhos não sobrepostos em cada totalizando, para cada temperatura de secagem utilizada, quatro repetições. A temperatura e a umidade relativa do ar ambiente onde se encontrava a estufa foram monitoradas por meio de psicrômetro instalado próximo à estufa, contendo as amostras.

O teor de água inicial das folhas de erva baleeira, ao início dos tratamentos de secagem foi de, aproximadamente, $75 \%$ b.u.. A secagem das folhas de erva baleeira prosseguiu até que o produto atingisse o teor de água de equilíbrio com as condições de temperatura avaliadas neste trabalho, que foram 6,60; 5,22; 3,42 e 2,95\% b.u., respectivamente para as temperaturas de 40, 50, 60, $70^{\circ} \mathrm{C}$, possibilitando o cálculo da razão de umidade (Equação 1). Para fins de modelagem matemática, uma vez que ao final do processo de secagem ocorre grande variação de tempo para pouca variação de razão de umidade, prejudicando o ajuste matemático aos dados observados, considerou-se o fim da secagem quando o teor de água do produto

Rev. Bras. PI. Med., Campinas, v.16, n.2, supl. I, p.434-443, 2014. 
estivesse próximo de $10 \%$ b.u..

Durante o processo de secagem, a massa das bandejas contendo as amostras era aferida periodicamente. Foi utilizada uma balança digital de $0,001 \mathrm{~g}$ de resolução. O tempo entre as leituras foi controlado por meio da diferença de massas (método gravimétrico, conhecendo-se a massa e o teor de água inicial das folhas), com o objetivo de evitar grandes variações de teor de água entre as leituras. A partir de um teor de água previamente definido, era possível controlar em quanto tempo seria necessário se atingir a massa de produto que corresponderia ao teor de água estipulado, com a finalidade de se alcançar um número satisfatório de observações durante a secagem.

A razão de umidade ( $R U)$ das folhas da erva baleeira durante a secagem nas diferentes condições de ar, foi determinada por meio da seguinte expressão:

$$
R U=\frac{M-M_{e}}{M_{i}-M_{e}}
$$

em que

RU: razão de umidade do produto, admensional;

$\mathrm{M}$ : teor de água do produto, decimal (b.s.); decimal (b.s.);

$\mathrm{M}_{\mathrm{e}}$ : teor de água de equilíbrio do produto, (b.s.);

$\mathrm{M}_{\mathrm{i}}$ : teor de água inicial do produto, decimal

Aos dados experimentais de razão de umidade durante a secagem das folhas de erva baleeira foram ajustados oito modelos matemáticos tradicionalmente utilizados para predizer o fenômeno da secagem de produtos agrícolas. Na Tabela 1 encontram-se os modelos que foram avaliados neste trabalho.

O coeficiente de difusão efetivo das folhas de erva baleeira, para as diferentes condições de secagem $\left(40,50,60\right.$ e $\left.70^{\circ} \mathrm{C}\right)$, foi calculado utilizando a Equação 10, baseado na teoria da difusão líquida. Essa equação é a solução analítica para a segunda lei de Fick, considerando a forma geométrica plana do produto e com aproximação de oito termos.

$$
R U=\frac{M-M_{e}}{M_{i}-M_{e}}=\frac{8}{\pi^{2}} \sum_{n=0}^{\infty} \frac{1}{(2 n+1)^{2}} \exp \left[-(2 n+1)^{2} \cdot \pi^{2} D_{i}\left(\frac{t}{4 L}\right)^{2}\right]
$$

em que,

Di: coeficiente de difusão efetivo, $\mathrm{m}^{2} \mathrm{~s}^{-1}$;

$\mathrm{L}$ : espessura do produto, $\mathrm{m}$;

T: temperatura, ${ }^{\circ} \mathrm{C}$;

$\mathrm{n}$ : número de termos do modelo.

Para determinação da espessura das folhas de erva baleeira, foram realizadas 50 repetições por dia de coleta de material, utilizando-se um paquímetro digital com resolução de 0,01 mm. Uma vez que todas as folhas eram sempre colhidas nos primeiros horários da manhã, foram realizadas

\begin{tabular}{|c|c|c|}
\hline Designação do modelo & Modelo & \\
\hline Aproximação da difusão & $R U=a \exp (-k \theta)+(1-a) \exp (-k b \theta)$ & $(2)$ \\
\hline Dois termos & $\mathrm{RU}=\mathrm{a} \exp (-\mathrm{k} \theta)+\mathrm{b} \exp \left(-\mathrm{k}_{1} \theta\right)$ & (3) \\
\hline Exponencial de dois termos & $R U=a \exp (-k \theta)+(1-a) \exp (-k$ a $\theta)$ & (4) \\
\hline Henderson e Pabis modificado & $R U=a \exp (-k \theta)+b \exp \left(-k_{0} \theta\right)+c \exp \left(-k_{1} \theta\right)$ & (5) \\
\hline Logarítmico & $R U=a \exp (-k \theta)+c$ & (6) \\
\hline Midilli & $R U=a \exp \left(-k \theta^{n}\right)+b \theta$ & (7) \\
\hline Page & $R U=\exp \left(-k \theta^{n}\right)$ & $(8)$ \\
\hline Thompson & $R U=\exp \left\{\left[-a-\left(a^{2}+4 b \theta\right)^{0,5}\right] / 2 b\right\}$ & (9) \\
\hline
\end{tabular}

TABELA 1. Modelos matemáticos utilizados para estimar as curvas de secagem das folhas de erva baleeira

em que,

$\theta$ : tempo de secagem, s;

$\mathrm{k}, \mathrm{k}_{0}, \mathrm{k}_{1}$ : constantes de secagem, $\mathrm{s}^{-1}$;

$\mathrm{a}, \mathrm{b}, \mathrm{c}$, : coeficientes dos modelos

Rev. Bras. PI. Med., Campinas, v.16, n.2, supl. I, p.434-443, 2014. 
quatro coletas em quatro dias diferentes, para cada temperatura do ar de secagem utilizada. Para cada folha medida, eram feitas 3 medições em diferentes locais.

Para avaliar a influência da temperatura no coeficiente de difusão efetivo, foi utilizada a equação de Arrhenius, descrita da seguinte forma:

$$
D_{i}=D_{0} \exp \left(\frac{E_{a}}{R T_{a}}\right)
$$

em que,

$\mathrm{D}_{0}$ : fator pré-exponencial;

$\mathrm{E}_{\mathrm{a}}$ : energia de ativação, $\mathrm{kJ} \mathrm{mol}^{-1}$;

$\mathrm{R}$ : constante universal dos gases, $8,314 \mathrm{~kJ} \mathrm{kmol}^{-1}$ $\mathrm{K}^{-1} ; \mathrm{e}$

Ta: temperatura absoluta, $\mathrm{K}$.

Os dados experimentais de cinética de secagem da erva baleeira foram submetidos à análise de regressão e seleção do modelo matemático adequado para expressar a relação entre as variáveis estudadas. Para o ajuste dos modelos matemáticos aos dados experimentais, foi utilizado o programa computacional STATISTICA 7.0๑. Para análise do grau de ajuste de cada modelo, foram consideradas as magnitudes do coeficiente de determinação ajustados (variância explicada), do erro médio relativo e desvio padrão da estimativa, além da verificação do comportamento da distribuição dos resíduos. Os valores do erro médio relativo $(P)$ e do desvio padrão da estimativa (SE) foram calculados conforme descrito a seguir:

$$
\begin{aligned}
& P=\frac{100}{n} \sum_{i=1}^{n}\left(\frac{|Y-\hat{Y}|}{Y}\right) \\
& S E=\sqrt{\frac{\sum_{i=1}^{n}(Y-\hat{Y})^{2}}{G L R}}
\end{aligned}
$$

$\mathrm{n}$ = número de observações experimentais;

$Y=$ valor observado experimentalmente;

$\hat{Y}=$ valor calculado pelo modelo;

GLR = graus de liberdade do modelo .

\section{RESULTADO E DISCUSSÃO}

$\mathrm{Na}$ Tabela 2, encontram-se os valores dos parâmetros estatísticos desvio padrão da estimativa (SE), erro médio relativo $(P)$ e o coeficiente de determinação $\left(R^{2}\right)$, utilizados para a comparação entre os oito modelos ajustados aos dados experimentais de cinética de secagem das folhas de erva baleeira sob diferentes condições de temperatura do ar de secagem utilizadas.

Observa-se na Tabela 2 que para todas as temperaturas utilizadas na secagem das folhas de erva baleeira os modelos matemáticos ajustados aos dados experimentais, apresentaram coeficientes de determinação $\left(R^{2}\right)$ superiores a $97 \%$, o que segundo Madamba et al. (1996) e Kashaninejad et al. (2007), indicam representação satisfatória destes modelos para o fenômeno de secagem estudado. Mohapatra \& Rao (2005) relatam que a utilização do coeficiente de determinação como o único critério de avaliação para a seleção dos modelos de secagem não constitui um bom parâmetro, sendo necessária a análise conjunta de outros parâmetros estatísticos.

Ainda na Tabela 2, constata-se que, para todas as temperaturas analisadas durante a secagem das folhas de erva baleeira, apenas o modelo proposto por Midilli apresenta magnitudes do erro médio relativo inferior a $10 \%$. Mohapatra \& Rao (2005) consideram modelos com valores de erro médio relativo superiores a $10 \%$ inadequados para a descrição de um determinado fenômeno, em especial o de secagem. Segundo Kashaninejad et al. (2007) os valores do erro médio relativo indicam desvio dos valores observados em relação à curva estimada pelo modelo. Apesar de a análise da Tabela 2 nos mostrar que ao se considerar uma temperatura isoladamente outros modelos apresentaram valores da magnitude do erro médio relativo inferior a $10 \%$, sendo adequada sua utilização na representação da secagem das folhas de erva baleeira, optou-se neste trabalho também incluir o valor do erro médio relativo inferior a $10 \%$ para todas as temperaturas como critério.

Além dos valores do coeficiente de determinação e do erro médio relativo, também foram calculados os valores do desvio padrão da estimativa (Tabela 2). Percebe-se na Tabela 2 que, em geral, os modelos de Midilli e Henderson e Pabis modificado foram os que apresentaram as menores magnitudes do desvio padrão da estimativa dentre todos os testados para todas as temperaturas testadas. De acordo com Draper e Smith (1998), a capacidade de um modelo para descrever com fidelidade um determinado processo físico é inversamente proporcional ao valor do desvio padrão da estimativa. Dessa forma, quanto menor for o valor do desvio padrão da estimativa (SE), melhor será a qualidade de ajuste do modelo em relação aos dados observados.

Assim, com base em todos os parâmetros estatísticos utilizados, recomenda-se o modelo

Rev. Bras. PI. Med., Campinas, v.16, n.2, supl. I, p.434-443, 2014. 
TABELA 2. Parâmetros estatísticos para os modelos de secagem das folhas de erva baleeira

\begin{tabular}{|c|c|c|c|c|c|c|}
\hline \multirow{2}{*}{ Modelos } & \multicolumn{3}{|l|}{$40^{\circ} \mathrm{C}$} & \multicolumn{3}{|l|}{$50^{\circ} \mathrm{C}$} \\
\hline & $\begin{array}{l}\text { SE } \\
\text { (decimal) }\end{array}$ & $\mathrm{P}(\%)$ & $\begin{array}{l}\mathrm{R}^{2} \\
\text { (decimal) }\end{array}$ & $\begin{array}{l}\text { SE } \\
\text { (decimal) }\end{array}$ & $\mathrm{P}(\%)$ & $\begin{array}{l}\mathrm{R}^{2} \\
\text { (decimal) }\end{array}$ \\
\hline Aproximação da difusão & 0,0199 & 29,4939 & 0,9967 & 0,0054 & 6,7766 & 0,9998 \\
\hline Dois termos & 0,0128 & 13,3082 & 0,9987 & 0,0225 & 25,2478 & 0,9962 \\
\hline Exponencial de dois termos & 0,0138 & 16,2674 & 0,9983 & 0,0079 & 10,6276 & 0,9994 \\
\hline Henderson e Pabis modificado & 0,0085 & 7,9492 & 0,9995 & 0,0041 & 4,8645 & 0,9999 \\
\hline Logarítmico & 0,0101 & 8,7391 & 0,9991 & 0,0073 & 8,9248 & 0,9996 \\
\hline Midilli & 0,0110 & 8,6641 & 0,9991 & 0,0043 & 5,0321 & 0,9999 \\
\hline Page & 0,0155 & 18,1886 & 0,9978 & 0,0083 & 10,2284 & 0,9994 \\
\hline Thompson & 0,0192 & 29,4971 & 0,9967 & 0,0225 & 28,3210 & 0,9954 \\
\hline \multirow{2}{*}{ Modelos } & \multicolumn{3}{|l|}{$60^{\circ} \mathrm{C}$} & \multicolumn{3}{|l|}{$70^{\circ} \mathrm{C}$} \\
\hline & $\begin{array}{l}\text { SE } \\
\text { (decimal) }\end{array}$ & $\mathrm{P}(\%)$ & $\begin{array}{l}\mathrm{R}^{2} \\
\text { (decimal) }\end{array}$ & $\begin{array}{l}\text { SE } \\
\text { (decimal) }\end{array}$ & $\mathrm{P}(\%)$ & $\begin{array}{l}\mathrm{R}^{2} \\
\text { (decimal) }\end{array}$ \\
\hline Aproximação da difusão & 0,0304 & 32,4253 & 0,9945 & 0,0210 & 10,4615 & 0,9969 \\
\hline Dois termos & 0,0188 & 13,4929 & 0,9982 & 0,0205 & 9,0591 & 0,9975 \\
\hline Exponencial de dois termos & 0,0187 & 18,4693 & 0,9976 & 0,0099 & 10,0299 & 0,9992 \\
\hline Henderson e Pabis modificado & 0,0280 & 19,2884 & 0,9977 & 0,0063 & 4,3210 & 0,9998 \\
\hline Logarítmico & 0,0315 & 33,3729 & 0,9941 & 0,0209 & 10,6152 & 0,9970 \\
\hline Midilli & 0,0149 & 9,3618 & 0,9989 & 0,0039 & 3,0484 & 0,9999 \\
\hline Page & 0,0139 & 6,9311 & 0,9987 & 0,0064 & 5,8703 & 0,9997 \\
\hline Thompson & 0,0543 & 62,1057 & 0,9796 & 0,0468 & 38,3224 & 0,9826 \\
\hline
\end{tabular}

de Midilli para a representação do fenômeno de secagem das folhas de erva baleeira. Radünz et al. (2011) trabalhando com carqueja, Prates et al. (2012) trabalhando com folhas de fruta-de-lobo, Evin (2012) trabalhando com Gundelia tourneforti L., Martinazzo et al. (2007) trabalhando com folhas de capim limão e Reis et al. (2012) trabalhando com folhas de manjericão, também concluíram que o modelo de Midilli foi o que melhor se ajustou aos dados experimentais de secagem destas plantas medicinais.

Na Figura 1, são apresentadas, para todas as condições de secagem estudadas, comparações entre os valores observados e os estimados, pelo modelo de Midilli, da razão de umidade das folhas de erva baleeira durante a secagem.

De acordo com a figura 1, observa-se que o aumento da temperatura do ar de secagem promove uma redução no tempo necessário para a remoção de água do produto, fenômeno esse observado por diversos pesquisadores também trabalhando com outras espécies de plantas medicinais (Evin 2012; Prates et al., 2012; Reis et al., 2012; Rocha et al., 2012; Kadam et al., 2011; Radünz et al., 2011; Martinazzo et al., 2010; Premi et al., 2010; Martinazzo et al., 2007; Doymaz, 2006). Observase na Figura 1, que para as folhas da erva baleeira atingissem o teor de água de, aproximadamente, $10 \%$ b.u., foram necessárias 11,$5 ; 4,0 ; 2,0$ e 1,1 horas, para as temperaturas de $40 ; 50 ; 60$ e $70^{\circ} \mathrm{C}$, respectivamente.

$\mathrm{Na}$ Figura 2, são apresentadas, para todas as condições de secagem estudadas, comparações entre os valores observados e os estimados, pelo modelo de Midilli, da razão de umidade das folhas de erva baleeira, durante a secagem. A análise desse gráfico permite evidenciar o bom ajuste do modelo de Midilli aos dados observados, devido a proximidade dos dados observados à linha de $45^{\circ}$, o que vem reforçar a aplicabilidade do modelo na predição dos dados de secagem das folhas de erva baleeira.

Na Tabela 3 são apresentados, os coeficientes do modelo de Midilli (Equação 7) ajustados aos dados observados da cinética de secagem das folhas de erva baleeira para as 


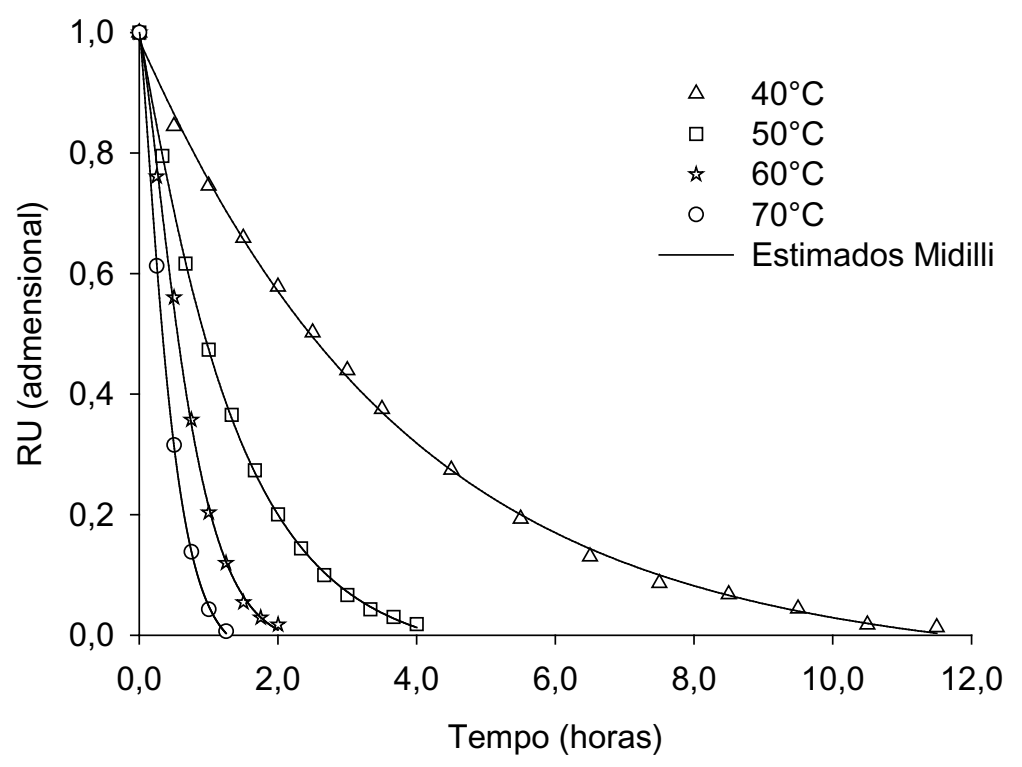

FIGURA 1. Razão de umidade experimentais e estimados pelo modelo de Midilli para a secagem das folhas de erva baleeira

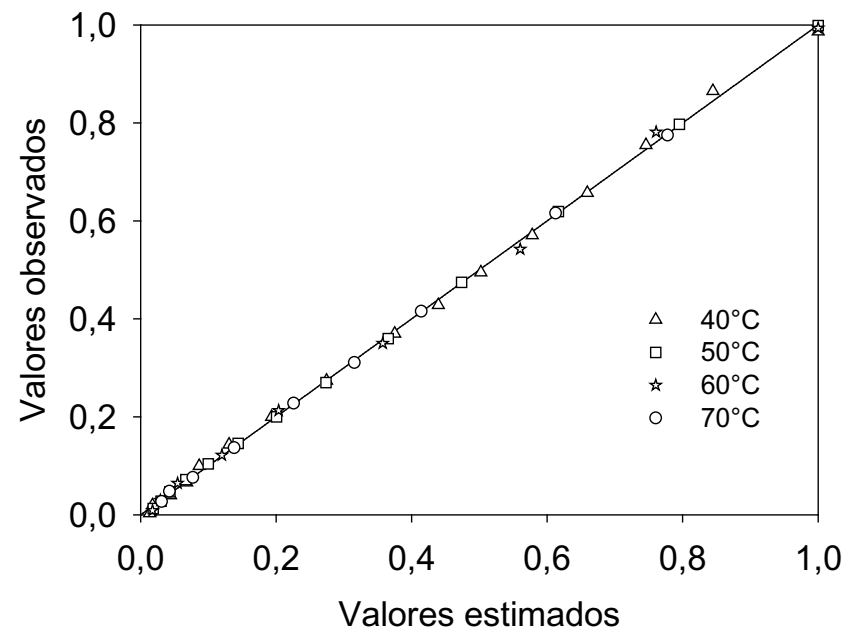

FIGURA 2. Valores de razão de umidade observados e estimados pelo modelo de Midilli para a secagem das folhas de erva baleeira

diferentes temperaturas do ar de secagem utilizadas.

De acordo com a Tabela 3, observa-se que somente os parâmetros (k) e (b) do modelo de Midilli apresentaram tendência na variação da magnitude de seus valores com a variação da temperatura do ar de secagem. Com a elevação da temperatura do ar de secagem houve aumento nos valores encontrados para os parâmetros $(k)$ e (b), sendo que, para os parâmetros (a) e (n), não houve nenhuma tendência observada. As variações dos parâmetros (b), (a) e (n) se devem mais a ajustes matemáticos do que relacionados a algum fenômeno de secagem, uma vez que o modelo de Midilli é um modelo semi-empírico (Midilli et al., 2002). A constante de secagem (k), que representa as condições externas de secagem, pode ser utilizada como uma aproximação para caracterizar o efeito da temperatura e está relacionada com a difusividade efetiva no processo de secagem no período decrescente e à difusão liquida que controla o processo (Babalis \& Belessiotis, 2004).

A relação do parâmetro (k) e (b) do modelo de Midilli em função da temperatura do ar de secagem das folhas de erva baleeira pode ser descrita, respectivamente, pelas equações lineares a seguir:

$k=0,0816 T-3,1788 \quad(R 2=0,9596)$

$b=-0,0004 T+0,0157 \quad(R 2=0,8049)$ 
TABELA 3. Parâmetros do modelo de Midilli para a secagem das folhas de erva baleeira

\begin{tabular}{lllll}
\hline Temperatura $\left({ }^{\circ} \mathrm{C}\right)$ & $\mathrm{a}$ & $\mathrm{k}$ & $\mathrm{n}$ & $\mathrm{b}$ \\
\hline 40 & 0,9869 & 0,2638 & 1,0247 & $-0,0031$ \\
50 & 0,9986 & 0,7311 & 1,0823 & $-0,0062$ \\
60 & 0,9936 & 1,5093 & 1,3319 & $-0,0067$ \\
70 & 1,0004 & 2,7229 & 1,2552 & $-0,0175$ \\
\hline
\end{tabular}

Podemos observar nas Equações 14 e 15, elevadas magnitudes do coeficiente de determinação $\left(R^{2}\right)$, referentes às equações utilizadas para descrever os valores do parâmetro (k) e (b) do modelo de Midilli em função da temperatura do ar. Utilizando estas equações, juntamente com a média dos valores do parâmetro (n) e (a), para todas as condições do ar de secagem, pode-se estimar o teor de água das folhas de erva baleeira em função do tempo e da temperatura do ar de secagem por meio da seguinte expressão:

$$
M=M_{e}+\left(M_{i}-M_{e}\right)\left\{0,9949 \exp \left[-(0,0816 T-3,1788) \theta^{1,1735}\right]+(-0,0004 T+0.0157) \theta\right\}
$$

em que:

$\mathrm{T}$ : temperatura em ${ }^{\circ} \mathrm{C}$; e

$\theta$ : tempo em horas.

$\mathrm{Na}$ Tabela 4, são apresentados os valores médios do coeficiente de difusão efetivo obtidos durante a secagem das folhas de erva baleeira, para diferentes condições de temperatura do ar, considerando a espessura média encontrada de $0,6623 \mathrm{~mm}$ para a erva baleeira.

Observando a Tabela 4, podemos notar que os valores do coeficiente de difusão efetivo aumentaram com o incremento da temperatura do ar de secagem. Quando há aumento da temperatura, a viscosidade da água diminui e, sendo a viscosidade uma medida da resistência do fluído ao escoamento, variações dessa propriedade implicam em alterações na difusão da água nos capilares das folhas de erva baleeira de modo a favorecer a movimentação desse fluído no produto. Outro fator que podemos acrescentar a essa variação do coeficiente de difusão efetivo é que, com a elevação da temperatura, aumenta-se o nível de vibração das moléculas de água, o que também contribui para uma difusão mais rápida (Goneli et al., 2007). De acordo com Rizvi (1995), o coeficiente de difusão efetivo é dependente da temperatura do ar de secagem, além da variedade e composição dos materiais, dentre outros.

A variação entre os valores do coeficiente de difusão ficaram entre 1,1294 a 9,4933 × 10-11 $\mathrm{m}^{2}$ $\mathrm{s}^{-1}$ para erva baleeira na faixa de temperatura de 40 a $70^{\circ} \mathrm{C}$. Os valores do coeficiente de difusão efetivo calculados para folhas de erva baleeira, estão coerentes com os relatados na literatura para secagem de produtos agrícolas que, de acordo com Madamba et al. (1996), apresentam-se na ordem de $10^{-9}$ a $10^{-11} \mathrm{~m}^{2} \mathrm{~s}^{-1}$.

A dependência do coeficiente de difusão efetivo com relação à temperatura do ar de secagem tem sido satisfatoriamente descrita pela equação de Arrhenius (Corrêa et al., 2007; Goneli et al., 2007; Martinazzo et al., 2007; Resende et al., 2007). A Figura 3 mostra os valores de In (D) em função do inverso da temperatura absoluta $\left(1 / \mathrm{K}^{-1}\right)$ obtidos para as folhas de erva baleeira.

A inclinação da curva da representação de Arrhenius fornece a relação $E a / R$, enquanto a sua

TABELA 4. Coeficiente de difusão efetivo durante a secagem de folhas de erva baleeira

\begin{tabular}{ll}
\hline Temperatura $\left({ }^{\circ} \mathrm{C}\right)$ & $\mathrm{D} \times 10^{-11}\left(\mathrm{~m}^{2} \mathrm{~S}^{-1}\right)$ \\
\hline 40 & 1,1294 \\
50 & 3,1994 \\
60 & 5,9511 \\
70 & 9,4933 \\
\hline
\end{tabular}

Rev. Bras. PI. Med., Campinas, v.16, n.2, supl. I, p.434-443, 2014. 


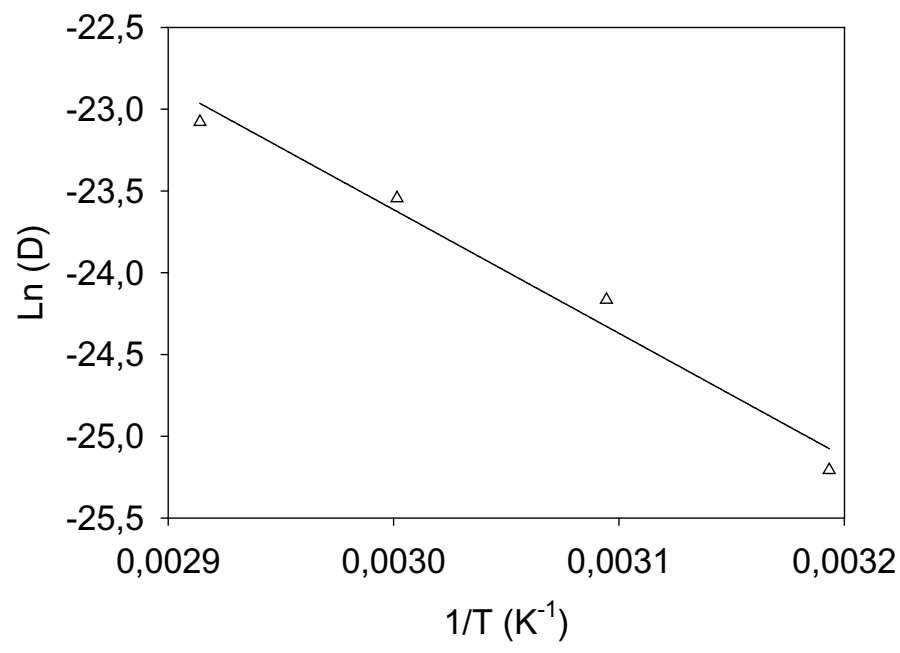

FIGURA 3. Representação de Arrhenius para o coeficiente de difusão efetivo, em função da temperatura do ar, durante a secagem das folhas de erva baleeira

interseção com o eixo das ordenadas indica o valor de $D_{0}$. A Equação 17 apresenta o coeficiente da equação de Arrhenius ajustadas para os coeficientes de difusão efetivo das folhas de erva baleeira, calculado de acordo com a Equação 11.

$$
D_{i}=0,3974 \exp \left(-\frac{62 \cdot 885,1189}{R T_{a}}\right)
$$

Como pode ser observada na Equação 19, a energia de ativação para a difusão da água durante a secagem das folhas de erva baleeira foi de 62,89 $\mathrm{kJ} \mathrm{mol}^{-1}$. Este valor se assemelha ao encontrado por Martinazzo et al. (2007) para folhas de capim-limão (63,47 kJ mol-1) e Doymaz (2006) para folhas de Mentha spicata L. $\left(62,96 \mathrm{~kJ} \mathrm{~mol}^{-1}\right)$. Nos processos de secagem, quanto menor a energia de ativação maior será a difusividade de água no produto. A energia de ativação é uma barreira que deve ser ultrapassada para que o processo de difusão possa ser desencadeado no produto (Kashaninejad et al., 2007). Segundo Zogzas et al. (1996), a energia de ativação para produtos agrícolas varia entre 12,7 a $110 \mathrm{~kJ} \mathrm{~mol}^{-1}$, estando a energia de ativação encontrada no presente trabalho dentro da faixa destes valores propostos por estes autores.

\section{CONCLUSÃO}

De acordo com os resultados encontrados neste trabalho, podemos concluir que:

O modelo matemático de Midilli, dentre todos os avaliados, foi o que apresentou melhor ajuste, sendo então o selecionado para a representação da cinética de secagem das folhas de erva baleeira;
O aumento da temperatura promoveu redução no tempo necessário para a remoção de água nas folhas de erva baleeira durante a secagem;

O coeficiente de difusão efetivo aumenta com a elevação da temperatura do ar de secagem e esta relação pode ser descrita pela equação de Arrhenius, que apresenta uma energia de ativação para a difusão líquida durante a secagem de 62,89 $\mathrm{kJ} \mathrm{mol}^{-1}$ para as folhas de erva baleeira.

\section{REFERÊNCIA}

ASABE. Moisture Measurement - Forages: Standard S358.2 DEC1988, R2008. In: AMERICAN SOCIETY OF AGRICULTURAL AND BIOLOGICAL ENGINEERS (Ed.). Standards, Engineering Practices, and Data. St. Joseph: ASABE, 2010. p.684-685.

BABALIS, S.J.; BELESSIOTIS, V.G. Influence of the drying conditions on the drying constants and moisture diffusivity during the thin-layer drying of figs. Journal of Food Engineering, v.65, n.3, p.449-458, 2004.

BERBERT, P.A.; QUEIROZ, D.M.; SILVA, J.S.; PINHEIRO FILHO, J.B. Simulation of coffee drying in a fixed bed with periodic airflow reversal. Journal of Agricultural Engineering Research, v.60, n.3, p.167-173, 1995.

CARVALHO JÚNIOR., P. M. ; RODRIGUES, R. F. O.; SAWAYA, A. C. H. F.; MARQUES, M. O. M.; SHIMIZU, M. T. Chemical composition and antimicrobial activity of the essential oil of Cordia verbenacea D.C. Journal of Ethnopharmacology, v.95, n.2-3, p.297-301, 2004.

CORREAA, P.C.; RESENDE, O.; MARTINAZZO, A.P.; GONELI, A.L.D.; BOTELHO, F.M. Modelagem matemática para a descrição do processo de secagem do feijão (Phaseolus vulgaris I.) em camadas delgadas. Engenharia Agrícola, v.27, n.2, p.501-507, 2007.

DOYMAZ, I. Thin-layer drying behaviour of mint leaves. Journal of Food Engineering, v.74, n.3, p.370-375, 
2006.

DRAPER, N. R.; SMITH, H. Applied regression analysis. 3.ed. New York: John Wiley \& Sons, 1998. 712 p.

EVIN, D. Thin layer drying of Gundelia tournefortii L. Food and Bioproducts processing, V.90, n.2, p.323-332, 2012.

GONELI, A. L. D.; CORREA, P. C.; RESENDE. O.; REIS NETO, S. A. Estudo da difusão de umidade em grãos de trigo durante a secagem. Ciência e Tecnologia de Alimentos, v.27, n.1, p.135-140, 2007.

KADAM, D.M.; GOYAL, R.K.; GUPTA, M.K. Mathematical modeling of convective thin layer drying of basil leaves. Journal of Medicinal Plants Research, v.5, n.19, p.4721-4730, 2011

KASHANINEJAD, M.; MORTAZAVI, A.; SAFEKORDI, A.; TABIL, L.G. Thin-layer drying characteristics and modeling of pistachio nuts. Journal of Food Engineering, v.78, n.1, p.98-108, 2007

KEEY, R.B. Drying: Principles and practice. New York: Pergamon Press. 1972. 358p.

LORENZI, H.; MATOS, F.J.A. Plantas medicinais no Brasil: nativas e exóticas. 2.ed. Nova Odessa: Plantarum, 2008. 544p.

MADAMBA, P.S.; DRISCOLL, R.H.; BUCKLE, K.A. Enthalpy-entropy compensation models for sorption and browning of garlic. Journal of Food Engineering, v.28, n.2, p.109-119, 1996

MARTINAZZO, A.P.; CORREAA, P.C.; RESENDE, O.; MELO, E.C. Análise e descrição matemática da cinética de secagem de folhas de capim-limão. Revista Brasileira de Engenharia Agrícola e Ambiental, v.11, n.3, p.301-306, 2007.

MARTINAZZO, A.P.; MELO, E.C.; CORRÊA, P.C.; SANTOS, R.H.S. Modelagem matemática e parâmetros qualitativos da secagem de folhas de Capim-limão [Cymbopogon citratus (DC.) Stapf]. Revista Brasileira de Plantas Medicinais, v.12, n.4, p.488-498, 2010.

MIDILLI, A.; KUCUK, H.; YAPAR, Z. A. New model for single-layer drying. Drying Technology, v.20, n.7, p.1503-1513, 2002.

MIGUEL, M. D.; MIGUEL, O. G. Desenvolvimento de fitoterápicos. 2.ed. Ribeirão Preto: Tecmedd. 2004. $115 p$.

MOHAPATRA, D.; RAO, P.S. A thin layer drying model of parboiled wheat. Journal of Food Engineering, v.66, n.4, p.513-518, 2005.

OZDEMIR, M.; DEVRES, Y. O. The thin layer drying characteristics of halzenuts during roasting. Journal of Food Engineering, v.42, n.4, p.225-233, 1999.

PANCHARIYA, P.C.; POPOVIC, D.; SHARMA, A.L. Thinlayer modeling of black tea drying process. Journal of Food Engineering, v.52, n.4, p.349-357, 2002.

PARK, K. J., VOHNIKOVA, Z., BROD, F.P.R. Evaluation of drying parameters and desorption isotherms of garden mint leaves (Mentha crispa L.). Journal of Food Engineering, v.51, n.3, p.193-199, 2002.

PASSOS, G. F.; FERNANDES, E. S.; CUNHA, F. M.; FERREIRA, J.; PIANOWSKI, L. F.; CAMPOS, M. M.; CALIXTO, J. B. Anti-inflamatory and anti-allergic properties of the essencial oil and active compounds from Cordia verbenacea. Journal of Ethnopharmacology, v.110, n.2, p.323-333, 2007.

PRATES, M.F.O.; REIS, R.C.; DEVILLA, I.A.; FARIA, R.Q.;
LIMA JUNIOR, A.F. Cinética de secagem de folhas de Solanum lycocarpum A. St.-Hil. (fruta-de-lobo). Revista Brasileira de Plantas Medicinais, v.14, n.3, p.514-521, 2012.

PREMI, M.; SHARMA, H.K.; SARKAR, B.C.; SINGH, C. Kinetics of drumstick leaves (Moringa oleifera) during convective drying. African Journal of Plant Science, v.4, n.10, p.391-400, 2010.

RADÜNZ, L.L.; AMARAL, A.S.; MOSSI, A.J.; MELO, E.C.; ROCHA, R.P. Avaliação da cinética de secagem de carqueja. Engenharia na Agricultura, v.19, n.1, p.1927, 2011.

REIS, R.C.; DEVILLA, I.A.; ASCHERI, D.P.R.; SERVULO, A.C.O.; SOUZA, A.B.M. Cinética de secagem de folhas de manjericão (Ocimus basilicum L.) via infravermelho. Revista Brasileira de Engenharia Agrícola e Ambiental, v.16, n.12, p.1346-1352, 2012.

RESENDE, O.; CORRÊA, P.C.; JARÉN, C.; MOURE, A.J. Bean moisture diffusivity and drying kinetics: a comparison of the liquid diffusion model when taking into account and neglecting grain shrinkage. Spanish Journal of Agricultural Research, v.5, n.1, p.51-58, 2007.

RIZVI, S.S.H. Thermodynamic properties of foods in dehydration. In: RAO, M.A.; RIZVI, S.S.H. Engineering properties of foods. New York: Academic Press, 1995. p. 223-309.

ROCA, E.; GUILLARD, V.; BROYART, B.; GUILBERT, S.; GONTARD, N. Effective moisture diffusivity modeling food structure and hygroscopicity. Food Chemistry, v.106, n.4, p.1428-1437, 2008.

ROCHA, R.P.; MELO, E.C.; CORBÍN, J.B.; BERBET, P.A.; DONZELES, S.M.L.; TABAR, J.A. Cinética del secado de tomillo. Revista Brasileira de Engenharia Agrícola e Ambiental, v.16, n.6, p.675-683, 2012.

SERTIÉ, J. A. A.; BASILE, A. C.; PANIZZA, S.; MATIDA, A. K.; ZELNIK, R. Pharmacological assay of Cordia verbenacea. Part 1. Anti-inflammatory activity and toxicity of the crude extracts of the leaves. Planta Medica, v.54, n.1, p.7-10, 1988.

SERTIÉ, J.A.A.; WOISKY, R.G.; WIEZEL, G.; RODRIGUES, M. Pharmacological assay of Cordia verbenacea V: oral and topical anti-inflamatory activity, analgesic effect and toxicity of a crude leaf extract. Phytomedicine, v.12, n.5, p.338-344, 2005

SOYSAL, Y.; ÖZTEKIN, S. Equilibrium moisture content equations for some medicinal and aromatic plants. Journal of agricultural Engineering Research, v.74, n.3, p.317-324, 1999.

TICLI, F. K.; HAGE, L. I. S.; CAMBRAIA, R. S.; PEREIRA, P. S.; MAGRO, A. J.; FONTES, M. R M.; STÁBELI, R. G.; GIGLIO, J. R.; FRANÇA, S. C.; SOARES, A. M.; SAMPAIO, S. V. Rosmarinic acid, a new snake venom phospholipase $A_{2}$ inhibitor from Cordia verbenacea (Boraginaceae): antiserum action potentation and molecular interaction. Toxicon, v.46, n.3, p.318-327, 2005.

VEIGA JUNIOR, V. F.; PINTO, A. C.; MACIEL, M. A. M. Plantas medicinais: cura segura? Química Nova, v.28, n.3, p.519-528, 2005.

ZOGZAS, N. P.; MAROULIS, Z. B.; MARINOS-KOURIS, D. Moisture diffusivity data compilation in foodstuffs. Drying Technology, v.14, n.10, p.2225-2253, 1996.

Rev. Bras. PI. Med., Campinas, v.16, n.2, supl. I, p.434-443, 2014. 